\title{
Towards Biological Control of Aspergillus carbonarius and Botrytis cinerea in Grapevine Berries and Transcriptomic Changes of Genes Encoding Pathogenesis-Related (PR) Proteins
}

\author{
Danai Gkizi (D), Eirini G. Poulaki and Sotirios E. Tjamos * \\ Laboratory of Plant Pathology, Agricultural University of Athens, 75 Iera Odos Str., 11855 Athens, Greece; \\ danai_gkizi@aua.gr (D.G.); poulakie@gmail.com (E.G.P.) \\ * Correspondence: sotiris@aua.gr
}

check for updates

Citation: Gkizi, D.; Poulaki, E.G.; Tjamos, S.E. Towards Biological Control of Aspergillus carbonarius and Botrytis cinerea in Grapevine Berries and Transcriptomic Changes of Genes Encoding Pathogenesis-Related (PR) Proteins. Plants 2021, 10, 970. https://doi.org/10.3390/ plants 10050970

Academic Editor: George Banilas

Received: 30 March 2021

Accepted: 10 May 2021

Published: 13 May 2021

Publisher's Note: MDPI stays neutral with regard to jurisdictional claims in published maps and institutional affiliations.

Copyright: (c) 2021 by the authors. Licensee MDPI, Basel, Switzerland. This article is an open access article distributed under the terms and conditions of the Creative Commons Attribution (CC BY) license (https:// creativecommons.org/licenses/by/ $4.0 /)$.

\begin{abstract}
Grapevine bunch rot, caused by Botrytis cinerea and Aspergillus carbonarius, causes important economic losses every year in grape production. In the present study, we examined the plant protective activity of the biological control agents, Paenibacillus alvei K165, Blastobotrys sp. FP12 and Arthrobacter sp. FP15 against B. cinerea and A. carbonarius on grapes. The in vitro experiments showed that strain K165 significantly reduced the growth of both fungi, while FP15 restricted the growth of A. carbonarius and FP12 was ineffective. Following the in vitro experiments, we conducted in planta experiments on grape berries. It was shown that K165, FP12 and FP15 reduced A. carbonarius rot severity by $81 \%, 57 \%$ and $37 \%$, respectively, compared to the control, whereas, in the case of $B$. cinerea, the only protective treatment was that with $\mathrm{K} 165$, which reduced rot by $75 \%$. The transcriptomic analysis of the genes encoding the pathogenesis-related proteins PR2, PR3, PR4 and PR5 indicates the activation of multiple defense responses involved in the biocontrol activity of the examined biocontrol agents.
\end{abstract}

Keywords: Arthrobacter sp.; Blastobotrys sp.; grapevine bunch rot; induced systemic resistance; Paenibacillus alvei

\section{Introduction}

Bunch rot of grape berries is caused by several pathogens such as Botrytis cinerea, several species of Aspergillus, Penicillium and Colletotrichum [1]; however, it is held that $B$. cinerea and $A$. carbonarius are the most significant. Grape berries are more prone to bunch rot at the ripening stage [2], when the use of fungicides is subject to increasing limitations for the avoidance of chemical residues in grapes and wines [3]. Therefore, bunch rot pathogens result in important economic losses to the producers, also affecting the quality of the wine [1]. The fact that B. cinerea, the major bunch rot causing pathogen in grape berries, is notorious for its ability to become resistant to fungicide treatments [4], in combination with the necessity to minimize the negative effects of pesticides on the environment, has led to an increasing interest in developing biocontrol-based disease management strategies [5,6]. In addition, A carbonarius (Bainier) Thom, causing sour rot, is among the predominant aspergilli in vineyards in several countries and, although it is a secondary invader, it is the major source of ochratoxin A in grapes [7-9], a mycotoxin with nephrotoxic, carcinogenic, teratogenic and immunosuppressive properties [10].

Even if a number of studies have been devoted to the biological control of $B$. cinerea and $A$. carbonarius in grapes, only the studies of Cordero et al. [11] and Diguta et al. [12] have identified microorganisms protecting grapes against both pathogens, reducing the disease severity by 50\% [11] and 75\% [12]. In the study of Cordero et al. [11], a strain of Pichia kluyveri was used to protect grapes against A. carbonarius and B. cinerea and Diguta et al. [12] reported the efficacy of two bacterial strains in reducing the decay incidence of grapes caused by the two pathogens. The mode of action of biocontrol agents 
against $B$. cinerea and $A$. carbonarius on grapes has been mainly attributed to antibiosis and competition for space and/or nutrients [11,12].

In the present study, we investigated whether the biocontrol agents Paenibacillus alvei K165, Arthrobacter sp. FP15 and Blastobotrys sp. FP12 can protect grape berries against B. cinerea and A. carbonarius. Previous studies have shown that strain K165 can protect plants from various soil-inhabiting pathogens such as Verticillium dahliae, Fusarium oxysporum f.sp. melonis, and Pythium ultimum, reducing disease severity by $50 \%$ compared with controls [13-15]. The plant protective activity of K165 lies mostly in its plant recognition by the FLS2 receptor and the subsequent induction of systemic resistance [16]. The FP12 and FP15 have been isolated from a $V$. dahliae suppressive compost [17] and previous studies have shown their plant protective activity against $V$. dahliae, Rhizoctonia solani and Sclerotinia sclerotiorum $[17,18]$. In these studies, the FP12 and FP15 strains reduced disease severity by $20 \%$ compared with controls $[17,18]$. The broad-spectrum activity of K165, FP12 and FP15 was the initiative used in our study to examine their activity against plant pathogens infecting the grape berries as pre- or post-harvest diseases. The aims of the study were to assess the biocontrol activity of K165, FP12 and FP15 in vitro and in planta against $B$. cinerea and $A$. carbonarius and investigate the defense triggering activity of the examined biocontrol agents against both pathogens, by following over time the expression of the genes encoding the pathogenesis-related (PR) proteins PR2, PR3, PR4 and PR5.

\section{Results}

\subsection{Biocontrol Efficacy of K165, FP12 and FP15 against B. cinerea and A. carbonarius}

The biocontrol efficacy of the examined biocontrol agents against $A$. carbonarius and $B$. cinerea was first evaluated in vitro, on potato dextrose agar (PDA) plates. The efficacy of K165 to inhibit the growth of both pathogens by $50 \%$ compared to the control was observed (Figure 1). On the other hand, the growth of $A$. carbonarius and B. cinerea was not affected by FP12, while FP15 reduced the growth of $A$. carbonarius but not of $B$. cinerea. Therefore, K165 produces metabolites with antibiotic activity against $A$. carbonarius and $B$. cinerea, as also happens for FP15 against $A$. carbonarius.

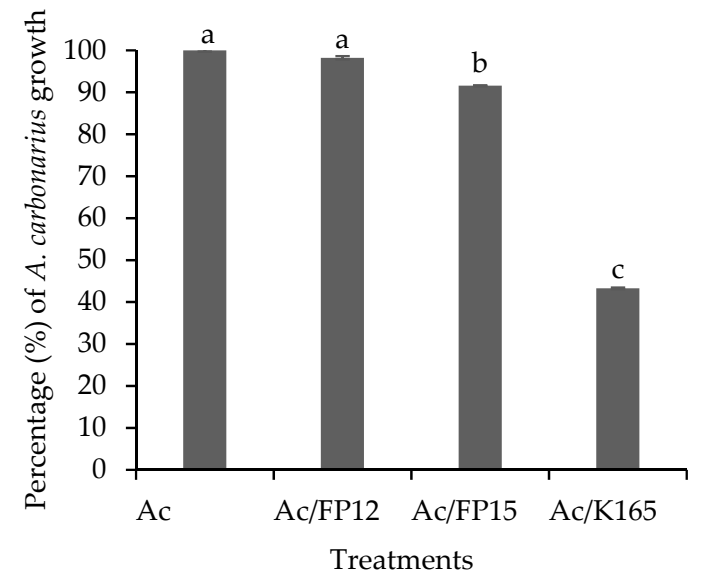

(a)

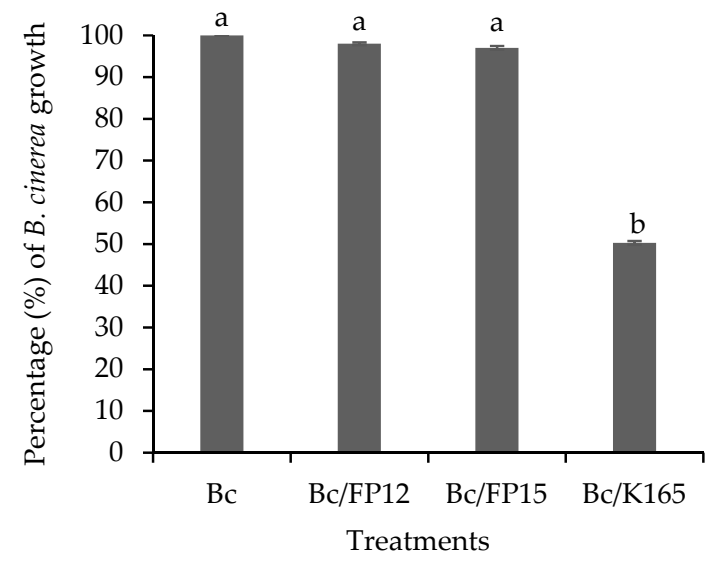

(b)

Figure 1. In vitro growth of Aspergillus carbonarius, Ac, (a) and Botrytis cinerea, Bc, (b) in dual culture with K165, FP12 and FP15 in PDA medium at 7 days after inoculation. The growth of the pathogen in the single culture (Ac or Bc) was set to $100 \%$ and its growth in the dual cultures was estimated as a percentage relative to the growth in the single culture. The columns represent the means of two biological repeats with three plates per treatment and repeated experiments $(n=6)$. Columns with different letters are significantly different from each other, according to Tukey's multiple range test $(p<0.05)$. The vertical bars indicate the standard error values. 
Following the in vitro experiments, we evaluated the efficacy of K165, FP12 and FP15 against $A$. carbonarius and $B$. cinerea on grape berries, collected at harvest time, of the red cultivar Fraoula, which is susceptible to both pathogens. The berries were immersed in a suspension of the examined biocontrol agents and after 2 days were puncture inoculated with each of the pathogens. At 7 days post pathogen inoculation (dpi), we recorded the growth of both pathogens in each treatment, by Image J. It was observed that K165 inhibited the growth of $B$. cinerea and $A$. carbonarius by $65 \%$ and $81 \%$, respectively, compared with the controls (Figure 2). The strains FP12 and FP15 reduced the growth of $A$. carbonarius by $57 \%$ and $28 \%$, respectively, compared to controls, but they were ineffective against $B$. cinerea. Therefore, the in planta results are partially consistent with the in vitro results, since the FP12 and FP15 strains reduced the in planta growth of $A$. carbonarius, in contrast to the in vitro data. The strain $\mathrm{K} 165$ had the most pronounced action against both pathogens, since it was the only effective biocontrol agent against $B$. cinerea and reduced the growth of A. carbonarius more than FP12 and FP15.

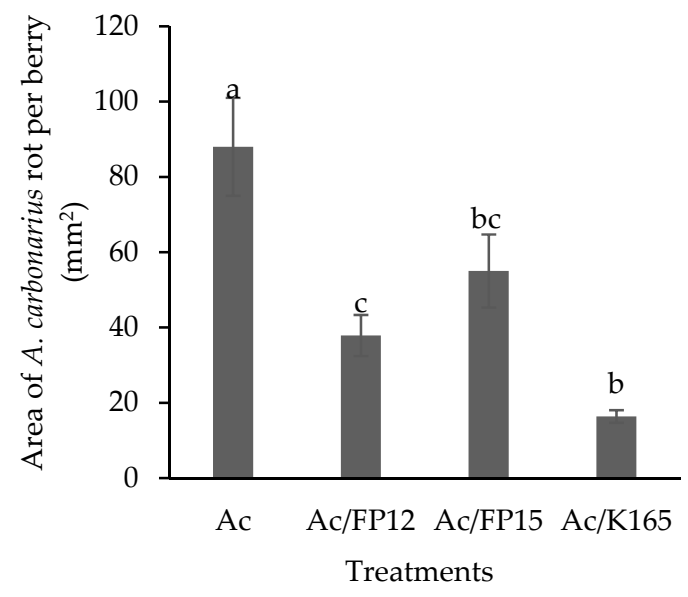

(a)

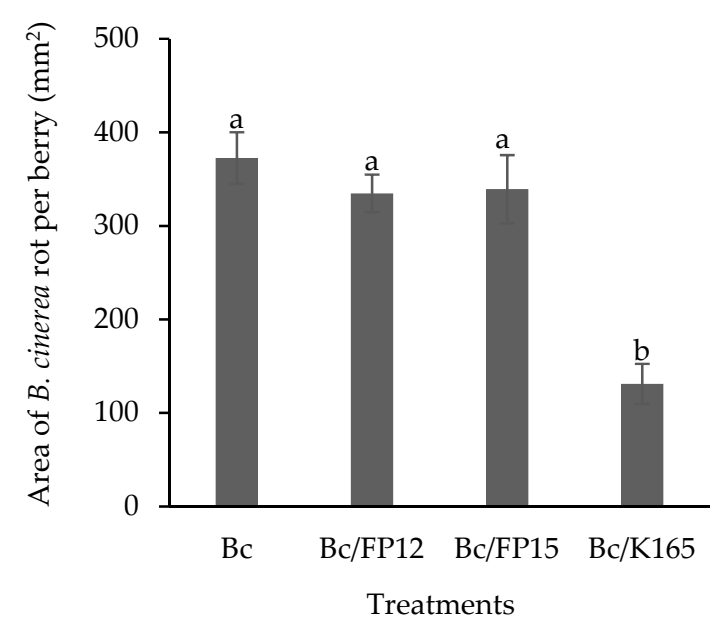

(b)

Figure 2. Area of Aspergillus carbonarius, Ac, (a) and Botrytis cinerea, Bc, (b) rot on grapes inoculated with K165, FP12 and FP15, at 7 days after pathogen inoculation. The columns represent the means of three biological repeats with eight berries per treatment and repeated experiments $(n=24)$. Columns with different letters are significantly different from each other, according to Nemenyi (a) and Tukey (b) multiple range tests $(p<0.05)$. The vertical bars indicate the values of the standard error.

\subsection{Transcriptomic Changes of PR2, PR $3, P R 4$ and PR5}

Following the in planta experiments, we questioned whether K165, FP12 and FP15 interfere with the defense mechanism of grapes. For this purpose, we examined the transcriptomic changes of $P R 2, P R 3, P R 4$ and PR5, after K165, FP12, FP15 and/or A. carbonarius and $B$. cinerea inoculation.

Upon A. carbonarius infection, the K165 pretreated grapes showed the highest PR2 levels among the different treatments, at 1 and 3 dpi (Figure 3a). Nevertheless, the expression of $P R 2$ in the FP12/A. carbonarius and FP15/A. carbonarius treatments was higher than the control, at both time points (Figure 3a). The expression of PR3 and PR4 in the biocontrol treated grapes was initially similar to the control at $1 \mathrm{dpi}$ and higher than the control at 3 dpi (Figure $3 b, c)$. In respect to the mock treatment, the $P R 3$ was downregulated in all treatments at 1 and $3 \mathrm{dpi}$, except of the K165/A. carbonarius treatment at 3 dpi (Figure 3b). On the other hand, PR4 was downregulated in all treatments at $1 \mathrm{dpi}$ and significantly overexpressed in the biocontrol treated grapes at 3 dpi (Figure 3c). The PR5 was downregulated in all treatments; however, the expression of PR5 in the K165/A. carbonarius treatment was higher than the control at both time points (Figure 3d), while the expression of PR5 
was higher in the FP12/A. carbonarius and FP15/A. carbonarius treatments compared with the control at $1 \mathrm{dpi}$ and $3 \mathrm{dpi}$, respectively (Figure $3 \mathrm{~d}$ ).

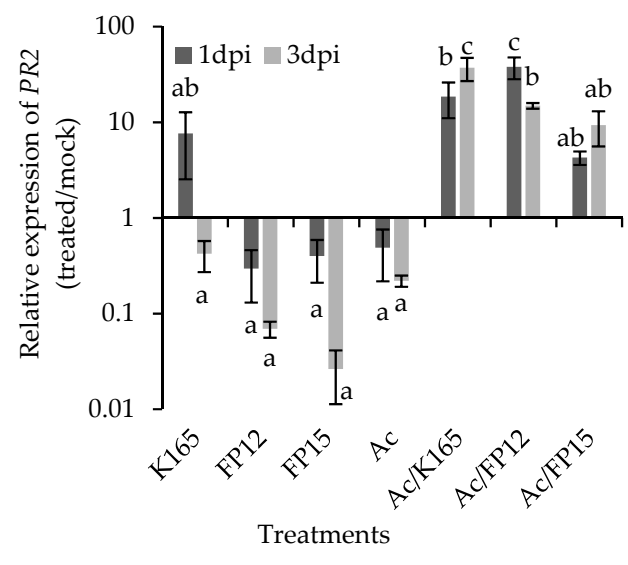

(a)

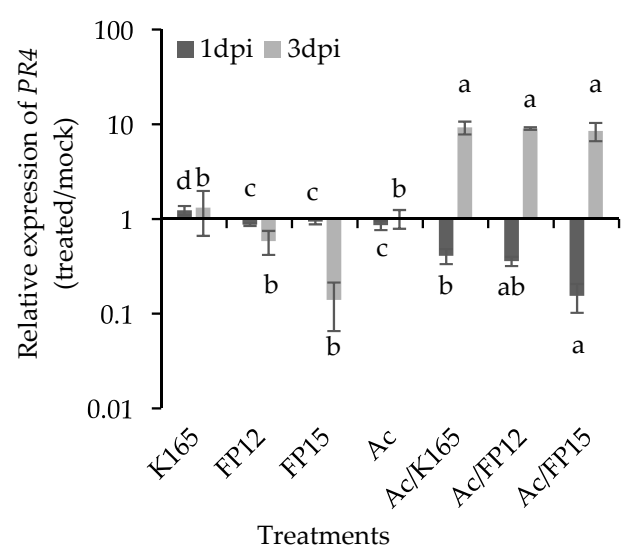

(c)

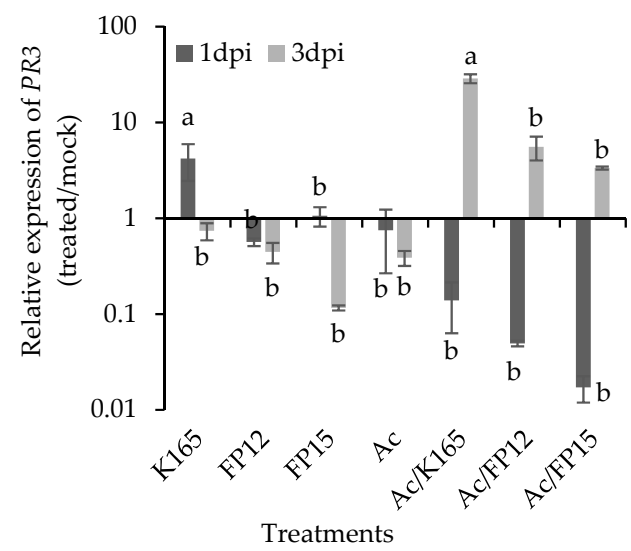

(b)

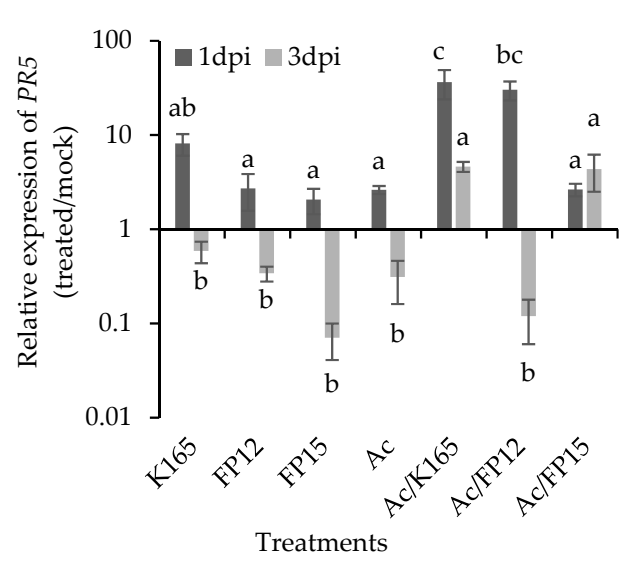

(d)

Figure 3. Relative transcript levels of $P R 2(\mathbf{a}), P R 3(\mathbf{b}), P R 4$ (c) and $P R 5$ (d) in the pericarp of grape berries treated with Paenibacillus alvei K165, Blastobotrys sp. strain FP12 or Arthrobacter sp. strain FP15 in response to infection with Aspergillus carbonarius. The samples for RNA isolation were collected at 1 and 3 days post inoculation (dpi) with the pathogen. The expression levels of $P R 2, P R 3, P R 4$ and $P R 5$ were normalized to the expression of $E F-1 a$ measured in the same samples and they are presented as transformed values with the $\log (x+1)$ transformation, in comparison with the normalized expression level of the respective gene in mock treatment. The columns show the means of three biological repeats $(n=3)$ and the results are presented on a logarithmic scale. The vertical bars indicate the standard errors. At each day, columns with different letters represent statistically different treatments according to the LSD test $(p<0.05)$.

Upon B. cinerea infection, the expression of $P R 2$ was upregulated in the K165 pretreated grapes at 1 and 3 dpi (Figure 4a), as was also observed for PR3, PR4 and PR5 at 3 dpi (Figure $4 \mathrm{~b}-\mathrm{d}$ ). In the case of the FP12 and FP15 pretreated grapes, the expression of PR2 was similar to the mock at 1 and $3 \mathrm{dpi}$ (Figure 4a), whereas the expression of PR3 and PR5 was downregulated at both time points (Figure $4 \mathrm{~b}, \mathrm{~d}$ ) and $P R 4$ expression was downregulated at $1 \mathrm{dpi}$ and upregulated at $3 \mathrm{dpi}$ (Figure 4c). Overall, the application of K165 caused significant higher expression levels of PR2 upon Botrytis infection, compared to the other treatments, at 1 and $3 \mathrm{dpi}$ (Figure 4a). Therefore, PR2 may have a role in the K165 mediated protection of grapes against $B$. cinerea. Additionally, a synergistic role of PR3 and PR5 with $P R 2$ at the later stages of the infection cannot be excluded, since the highest expression levels of PR3 and PR5 were detected in the K165/B. cinerea treatment, at 3 dpi (Figure 4b,d). 


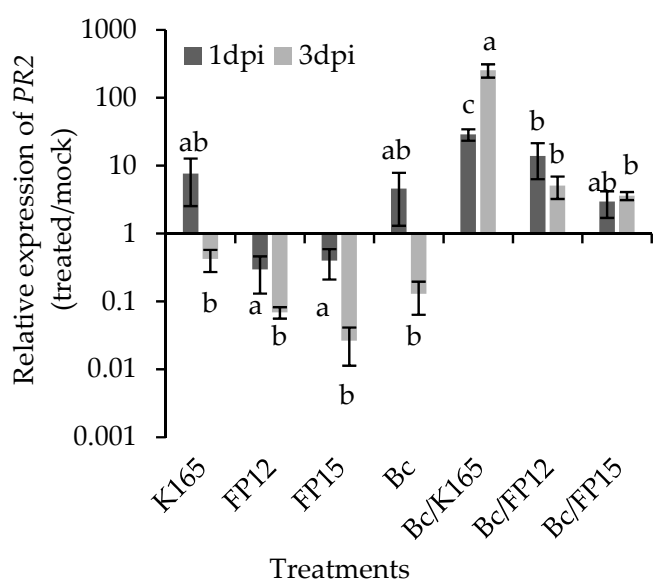

(a)

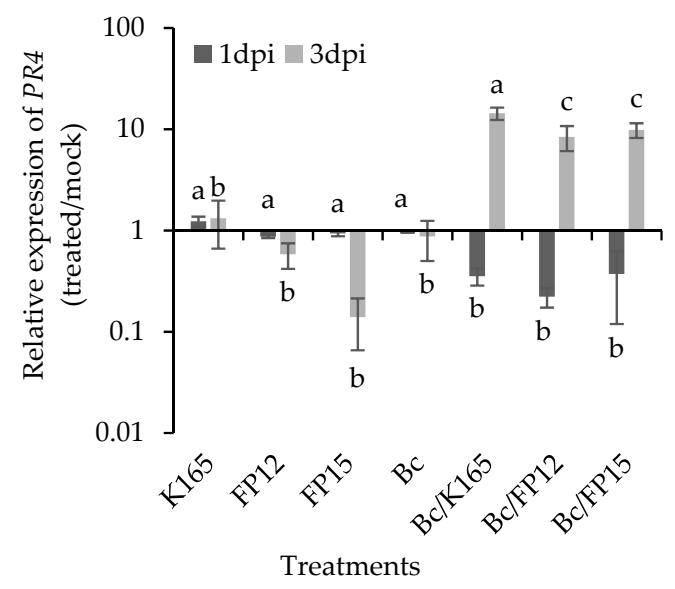

(c)

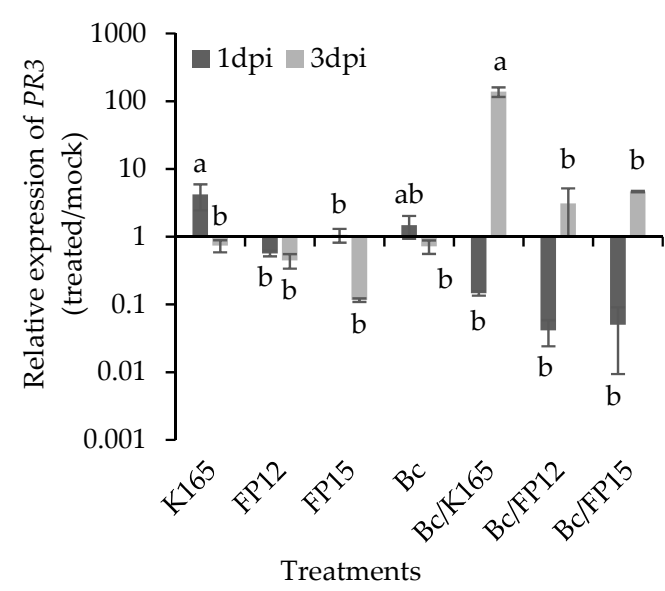

(b)

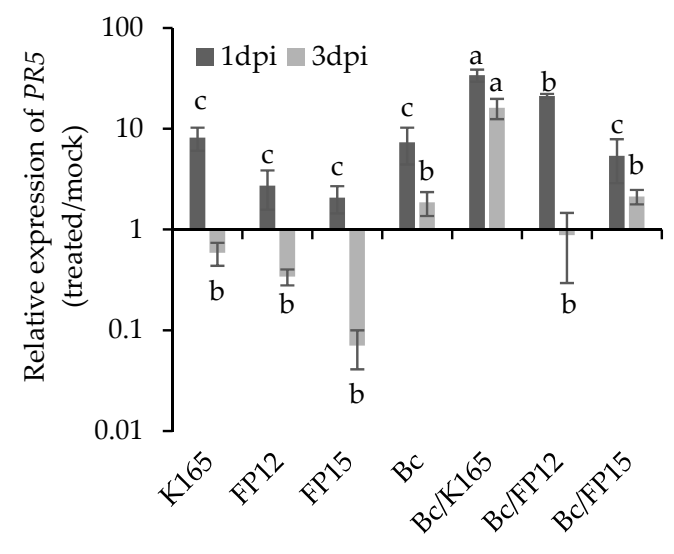

Treatments

(d)

Figure 4. Relative transcript levels of $P R 2$ (a), $P R 3(\mathbf{b}), P R 4$ (c) and $P R 5$ (d) in the pericarp of grape berries treated with Paenibacillus alvei K165, Blastobotrys sp. strain FP12 or Arthrobacter sp. strain FP15 in response to infection with Botrytis cinerea. The samples for RNA isolation were collected at 1 and 3 days post inoculation (dpi) with the pathogen. The expression levels of $P R 2, P R 3, P R 4$ and $P R 5$ were normalized to the expression of EF-1a measured in the same samples and they are presented as transformed values with the $\log (x+1)$ transformation, in comparison with the normalized expression level of the respective gene in mock treatment. The columns show the means of three biological repeats $(n=3)$ and the results are presented on a logarithmic scale. The vertical bars indicate the standard errors. At each day, columns with different letters represent statistically different treatments according to LSD test $(p<0.05)$.

\section{Discussion}

Biological control is the most appealing disease management strategy, if not the only one, for pathogens appearing close to harvest, due to the legislation for maximum residue levels. In parallel, the increasing problem of pesticide resistance poses a considerable threat for agriculture production and makes the development of biocontrol-based disease management strategies a way of no return. Having had research data showing the broadspectrum plant protective activity of the biocontrol agents P. alvei K165, Blastobotrys sp. FP12 and Arthrobacter sp. FP15 [15,17-19], we investigated their capacity to protect grape berries against $A$. carbonarius and $B$. cinerea, along with their plant defense triggering activity.

Our in vitro results showed that $P$. alvei K165 strain produces metabolites with antibiotic activity against $A$. carbonarius and $B$. cinerea. Indeed, Paenibacillus spp. are known to produce a number of antibiotics, like polymyxins and iturins and also cellulolytic enzymes [20]. In particular, Tjamos et al. [19] have shown that K165 released chitinolytic compounds in LB growth medium supplemented with glycol chitin. It is tempting to suggest that K165 may inhibit the growth of $B$. cinerea because of extracellular chitinases 
as it has been also suggested by Kim et al. [21] in the case of a Paenibacillus elgii strain against $B$. cinerea. Similarly, the K165 secreted chitinases may also be responsible for the inhibition of the in vitro growth of $A$. carbonarius, along with antibiotics such as iturins [22]. On the other hand, the Blastobotrys sp. FP12 strain did not reduce the in vitro growth of A. carbonarius and B. cinerea, while the Arthrobacter sp. FP15 strain secreted compounds inhibitory only for A. carbonarius, even if Arthrobacter species are known to secrete chitinase and antibiotic compounds with growth inhibitory effects against a broad range of plant pathogenic fungi $[17,23,24]$. Irrespectively of the in vitro data, we cannot exclude the possibility that FP12 and FP15 may produce an array of inhibitory substances against both pathogens, under favorable in vivo conditions, since factors like oxygen, water activity and $\mathrm{pH}$ influence microbial production of antibiotics [25].

Indeed, the in planta experiments on the grape berries, revealed the efficacy of the examined strains to reduce the disease severity of B. cinerea and A. carbonarius. The K165 strain reduced the disease severity of $B$. cinerea on grapes by $75 \%$, denoting its biocontrol efficacy, since in similar studies over the last decade the most efficacious biocontrol agents exhibited a biocontrol activity not exceeding $86 \%$ [26]. Similarly, the biocontrol activity of FP12 (57\%), FP15 (37\%) and mainly of K165 (81\%) against $A$. carbonarius is in the range of other biocontrol agents published in previous studies [27,28]. It is evident that the biocontrol traits of K165 are quite interesting, since its application resulted in a significant plant protection, up to $86 \%$, against B. cinerea and A. carbonarius.

In previous studies, strains belonging to Bacillus sp., the close relative of Paenibacillus, have been reported to control B. cinerea on grapes under vineyard and storage conditions, by secreting inhibitory compounds and triggering induced systemic resistance $[29,30]$. Similarly, it has been shown that Bacillus spp. control A. carbonarius on grapes, due to antibiosis [31]. Like in the case of K165, the FP12 and FP15 strains significantly reduced the $A$. carbonarius infection on grapes. This is the first published study reporting the plant protective activity of the genera Arthrobacter and Blastobotrys against $A$. carbonarius on grapes. As far as the mode of action of the yeast-like fungus FP12 is concerned, the main mode of action of the yeast-based biocontrol agents is competition for space and/or nutrients [32], even if the induction of host resistance and the production of antimicrobial compounds have been also reported in previous studies [33]. Among the different modes of action of the biocontrol agents, the induction of systemic resistance is held as the most preferable trait of biocontrol agents, since it offers plants an elevated level of protection against a broad spectrum of pathogens, without the necessity of a direct interaction between the pathogen and the biocontrol agent [34]. However, it is evident that biological control cannot compete the plant protective levels achieved by pesticides. In previous studies, the application of fludioxonil in combination with cyprodinil inhibited completely the growth of A. carbonarius and B. cinerea on grapes [35].

The pathogenesis-related proteins, including chitinases, glucanases and thaumatinlike proteins, accumulate in berries and leaves in response to pathogen invasion and are considered to contribute to grapevine resistance by decomposing the structural components of fungal cell walls [36]. The profile of PRs expression depends on the tissue type, developmental stage and also the invading pathogen or the abiotic stress $[37,38]$. In our experiments, we analyzed the effect of the examined biocontrol agents on the expression pattern of the chitinase encoding PR genes $P R 3$ and $P R 4$, the $\beta$-1,3-glucanase encoding gene $P R 2$ and the thaumatin-like protein expressing gene $P R 5$, upon $B$. cinerea and $A$. carbonarius infection.

Our transcriptomic results suggest the involvement of $P R 2$ and $P R 5$ in the K165 mediated protection against $B$. cinerea and $A$. carbonarius, since both genes showed the highest transcription levels in the $\mathrm{K} 165+B$. cinerea/A. carbonarius treatment, at both sampling points. The $P R 2$ was also upregulated in the plant protective FP12/FP15 + A. carbonarius treatments compared with the control, while its expression level was similar between the ineffective FP12/FP15 + B. cinerea treatments and control (B. cinerea). Therefore, the high $P R 2$ expression levels in the disease protective treatments $(\mathrm{K} 165+$ B. cinerea/A. carbonarius, 
FP12/FP15 + A. carbonarius) may underlie the biocontrol-mediated protection on grapes. On the other hand, the expression of PR5 did not show the consistency of PR2 over time, in the FP12/FP15 + A. carbonarius treatments.

The PR2 and PR5 are marker genes of the salicylic acid-dependent defense mechanisms and have been identified as key components of the biocontrol triggered plant defenses against $B$. cinerea [39]. The thaumatin-like proteins, $P R 5$, have been well associated with broad spectrum disease resistance in plants, including $B$. cinerea $[40,41]$. The PR5 proteins make the fungal cell membrane permeable, creating an osmotic imbalance and death of the cells [42]. In addition, some thaumatin-like proteins have a weak b-1,3-glucanase activity [43] and others act synergistically with chitinases against fungi [44,45]. In our experiments, the chitinase encoding $P R 3$ and $P R 4$ were overexpressed in the efficacious biocontrol treatments compared with control, at 3 dpi. The plant chitinases, except for inhibiting the growth of fungal hyphae by decomposing the chitin of the fungal cell wall [46], also participate in the pathogen-triggered immunity in plants, since the cleaved chitin oligomers from fungal cell walls are recognized by the plant cell receptor CERK1, triggering the downward plant defense mechanisms [47]. Furthermore, our results imply a synergistic action between $P R 2$ and $P R 3$ or $P R 4$ against $B$. cinerea and $A$. carbonarius, respectively, at $3 \mathrm{dpi}$. Indeed, the synergistic action between $\beta-1,3$-glucanase and chitinase against fungi has been well known since the 1980's [48]. Overall, our transcriptomic data suggest the triggering of certain aspects of the plant defense mechanism by the examined biocontrol agents, against $A$. carbonarius and B. cinerea.

In conclusion, our study provides novel data about the biocontrol activity of the Blastobotrys and Arthrobacter genera, since this is the first report about the biocontrol efficacy of strains belonging to these genera against $A$. carbonarius. In parallel, we observed the plant protective activity of $\mathrm{K} 165$ on grapes against $A$. carbonarius and $B$. cinerea; it becomes evident that K165 is a broad-spectrum biocontrol agent since it can protect various plant species against a wide range of plant pathogens. Our results suggest that K165 produces deleterious compounds for the growth of $A$. carbonarius and B. cinerea and induces the plant defense mechanisms, as has been also shown in previous studies against other pathogens. However, further studies in different grape varieties, temperature/humidity conditions and strains of $A$. carbonarius and $B$. cinerea are necessary, before concluding about the biocontrol activity of the examined strains.

\section{Materials and Methods}

\subsection{In Vitro Antagonism of K165, FP12 and FP15 against B. cinerea and A. carbonarius}

The dual culture technique described by Reddy and Patrick [49] was followed to examine the in vitro antagonism of K165, FP12 and FP15 against $B$. cinerea and $A$. carbonarius; both pathogens were isolated from infected grapes. In brief, K165, FP12 and FP15 grown on nutrient broth (Merck, Darmstadt, Germany) amended with $2 \%(v / v)$ glycerol (Merck, Darmstadt, Germany) and 1.5\% $(w / v)$ agar, were placed $2.5 \mathrm{~cm}$ from the edge of a Petri plate $(9 \mathrm{~cm}$ diameter) containing potato dextrose agar (PDA, Merck, Darmstadt, Germany) and allowed to grow for $48 \mathrm{~h}$ at $23^{\circ} \mathrm{C}$. Subsequently, a disc ( $5 \mathrm{~mm}$ diameter) of either of the pathogens, taken from the periphery of a freshly grown colony on PDA, was placed opposite to the examined biocontrol agent. The dual culture plates were incubated in the dark for 7 days at $23^{\circ} \mathrm{C}$. The growth of each pathogen was determined, 7 days after inoculation, by measuring the area covered with fungal hyphae, using the Image J software. The experiment was performed with a completely randomized design with three replications of each treatment and repeated twice.

4.2. Evaluation of the Antagonistic Activity of K165, FP12 and FP15 against A. carbonarius and $B$. cinerea in a Detached Berry Test

For the detached berry test, we followed the methodology of Dimakopoulou et al. [50]. The examined biocontrol agents were grown in liquid culture of nutrient broth amended with $2 \%(v / v)$ glycerol, in an orbital incubator at $150 \mathrm{rpm}$ for 2 days at $25{ }^{\circ} \mathrm{C}$. The bacterial 
suspensions were centrifuged at $5865 \mathrm{~g}$ for $10 \mathrm{~min}$, and resuspended in sterile distilled water (SDW), providing a cell concentration of $10^{8} \mathrm{cfu} \mathrm{mL}^{-1}$. Subsequently, surfacesterilized (0.05\% sodium hypochlorite for $10 \mathrm{~min}$, followed with $70 \%$ ethanol for $5 \mathrm{~min}$ and rinsed with SDW) berries of the grape variety Fraoula were immersed for 3 min in the cell suspension of the biocontrol agents containing 0.01\% Agral 90. Control berries were immersed in SDW containing 0.01\% Agral 90. Twenty-four hours later, a calibrated wound (ca $2 \mathrm{~mm}$ diameter) was made with a sterile needle on each berry. The wound was spotinoculated with $10 \mu \mathrm{L}$ spore suspension of $A$. carbonarius or $B$. cinerea $\left(10^{6}\right.$ spores $\left.\mathrm{mL}^{-1}\right)$, prepared from a freshly grown culture grown on PDA. Calibrated wounds were also made in mock-inoculated berries and berries treated only with the biocontrol agents. Grape berries were incubated at $25^{\circ} \mathrm{C}$.

The percentage of fungal growth on berries was determined 7 days after inoculation by measuring the area covered with fungal hyphae, using the Image J software. Each treatment consisted of eight replicates and the experiment was repeated thrice ( 24 berries).

\subsection{RNA Isolation and qPCR Determination of the Transcript Levels of Grapevine Defence Genes}

The plant defense triggering activity of K165, FP12 and FP15 was examined following the methodology described in Section 4.2. At 1 and $3 \mathrm{dpi}$, the pericarp tissue of 5 berries from each treatment (K165, FP12, FP15, K165/FP12/FP15 + A. carbonarius/B. cinerea, $A$. carbonarius / B. cinerea and mock) was harvested for measuring the expression levels of PR2, PR3, PR4 and PR5.

In brief, the pericarp tissue of 5 berries per treatment was pooled into one sample and ground to a fine powder in the presence of liquid nitrogen. For each sample, total RNA was extracted from $200 \mathrm{mg}$ of ground tissue, following the protocol of Sánchez et al. [51]. The RNA samples were treated with DNase I (New England Biolabs, Ipswich, MA, USA) to eliminate traces of contaminating genomic DNA. The RNA concentration was measured on a ND-1000 spectrophotometer (NanoDrop). First-strand cDNA was synthesized using an Xpert cDNA synthesis kit (Grisp) following the manufacturer's procedure. The expression levels of the PR2, PR3, PR4, and PR5 genes were detected by using the following primer sequences: PR2 (AJ277900) 5'-GGCTATGTTTGATTCCACTG-3' and $5^{\prime}$ TTGATTGGGTATTTAGCCTG-3' [52], PR3 (AF053341) 5'-GTTGGTGTGGCAACACTG-3' and 5'-CCTAAGTATATCACAGTACC-3' [52], PR4 (AF061329) 5'-CACAGCCGACTCACCCATG$3^{\prime}$ and 5'-GCAGAAGAAGCGGCTAACTCC-3' [52] and PR5 (Y10992) F 5'-CAGCTATGCAGC CACCTTC-3' and $5^{\prime}$-CCAAGGTGGATACCATTGC-3' [52]. The absence of nonspecific products and primer dimers was confirmed by the analysis of melting curves. The Elongation factor 1a $(E F-1 a)$ gene was used as an internal standard to normalize differences in cDNA template amounts using the primer sequences $5^{\prime}$-GAACTGGGTGCTTGATAGGC- $3^{\prime}$ and $5^{\prime}$ AACCAAAATATCCGGAGTAAAAGA-3' [53]. Average threshold cycle (Ct) values were calculated for each gene of interest on the basis of three independent biological samples.

\subsection{Statistics}

The experimental data, except of the data of the in planta test on $A$. carbonarius, were subjected to analysis of variance (ANOVA), followed by either Tukey's multiple range test for the in vitro and detached berries experiments or the least significant difference test for the gene expression experiments. The data of the gene expression experiments were transformed with the $\log (x+1)$ transformation before being subjected to ANOVA. The data of the in planta test on $A$. carbonarius had an irregular distribution; therefore, they were subjected to a Kruskal-Wallis test followed by Nemenyi's multiple range test.

Author Contributions: Conceptualization, S.E.T.; data curation, D.G. and S.E.T.; formal analysis, D.G.; investigation, D.G. and E.G.P.; methodology, D.G.; project administration, S.E.T.; resources, S.E.T.; supervision, S.E.T.; validation, D.G.; visualization, D.G. and S.E.T.; writing — original draft, D.G. and S.E.T.; writing-review and editing, D.G. and S.E.T. All authors have read and agreed to the published version of the manuscript. 
Funding: This research received no external funding.

Institutional Review Board Statement: Not applicable.

Informed Consent Statement: Not applicable.

Data Availability Statement: The data presented in this study are available on request from the corresponding author.

Acknowledgments: Authors acknowledge E. C. Tjamos for providing the K165 strain.

Conflicts of Interest: The authors declare no conflict of interest.

\section{References}

1. Steel, C.C.; Blackman, J.W.; Schmidtke, L.M. Grapevine Bunch Rots: Impacts on Wine Composition, Quality, and Potential Procedures for the Removal of Wine Faults. J. Agric. Food Chem. 2013, 61, 5189-5206. [CrossRef]

2. Kelloniemi, J.; Trouvelot, S.; Héloir, M.-C.; Simon, A.; Dalmais, B.; Frettinger, P.; Cimerman, A.; Fermaud, M.; Roudet, J.; Baulande, S.; et al. Analysis of the Molecular Dialogue between Gray Mold (Botrytis cinerea) and Grapevine (Vitis vinifera) Reveals a Clear Shift in Defense Mechanisms During Berry Ripening. Mol. Plant Microbe Interact. 2015, 28, 1167-1180. [CrossRef]

3. Verger, P.J.P.; Boobis, A.R. Reevaluate Pesticides for Food Security and Safety. Science 2013, 341, 717-718. [CrossRef]

4. Fernández-Ortuño, D.; Torés, J.A.; Chamorro, M.; Pérez-García, A.; De Vicente, A. Characterization of Resistance to Six Chemical Classes of Site-Specific Fungicides Registered for Gray Mold Control on Strawberry in Spain. Plant Dis. 2016, 100, 2234-2239. [CrossRef]

5. Elmer, P.A.G.; Reglinski, T. Biosuppression of Botrytis cinerea in grapes. Plant Pathol. 2006, 55, 155-177. [CrossRef]

6. Tracy, E.F. The promise of biological control for sustainable agriculture: A stakeholder-based analysis. J. Sci. Poly. Gov. 2014, 5.

7. Serra, R.; Abrunhosa, L.; Kozakiewicz, Z.; Venancio, A. Black Aspergillus species as ochratoxin A producers in Portuguese wine grapes. Int. J. Food Microbiol. 2003, 88, 63-68.

8. Battilani, P.; Giorni, P.; Bertuzzi, T.; Formenti, S.; Pietri, A. Black aspergilli and ochratoxin A in grapes in Italy. Int. J. Food Microbiol. 2006, 111, S53-S60. [CrossRef]

9. Bejaoui, H.; Mathieu, F.; Taillandier, P.; Lebrihi, A. Black aspergilli and ochratoxin A production in French vineyards. Int. J. Food Microbiol. 2006, 111, S46-S52. [CrossRef]

10. Battaglia, R.; Hatzold, T.; Kroes, R. Occurrence and significance of ochratoxin A in food. In Food Additives and Contaminants. In Proceedings of the Workshop on Ochratoxin in Food, Aix-en-Provence, France, 10-12 January 1996.

11. Cordero-Bueso, G.; Mangieri, N.; Maghradze, D.; Foschino, R.; Valdetara, F.; Cantoral, J.M.; Vigentini, I. Wild Grape-Associated Yeasts as Promising Biocontrol Agents against Vitis vinifera Fungal Pathogens. Front. Microbiol. 2017, 8, 2025. [CrossRef]

12. Diguță, C.F.; Matei, F.; Cornea, C.P. Biocontrol perspectives of Aspergillus carbonarius, Botrytis cinerea and Pencillium expansum on grapes using epiphytic bacteria isolated from Romanian vineyards. Rom. Biotech. Lett. 2016, 21, 11126-11132.

13. Tjamos, S.E.; Flemetakis, E.; Paplomatas, E.J.; Katinakis, P. Induction of Resistance to Verticillium dahliae in Arabidopsis thaliana by the Biocontrol Agent K-165 and Pathogenesis-Related Proteins Gene Expression. Mol. Plant Microbe Interact. 2005, 18, 555-561. [CrossRef]

14. Charalambous, A.; Tjamos, S.E.; Domazakis, E.; Paplomatas, E.J. Incorporation into the transplant soil plug of the plant protective agent Paenibacillus alvei strain K165 confers protection to melon against Fusarium wilt. BioControl 2007, 58, 685-692.

15. Fatouros, G.; Gkizi, D.; Fragkogeorgi, G.A.; Paplomatas, E.J.; Tjamos, S.E. Biological control of Pythium, Rhizoctonia and Sclerotinia in lettuce: Association of the plant protective activity of the bacterium Paenibacillus alvei K165 with the induction of systemic resistance. Plant Pathol. 2017, 67, 418-425.

16. Gkizi, D.; Lehmann, S.; L'Haridon, F.; Serrano, M.; Paplomatas, E.J.; Métraux, J.-P.; Tjamos, S.E. The Innate Immune Signaling System as a Regulator of Disease Resistance and Induced Systemic Resistance Activity against Verticillium dahliae. Mol. Plant Microbe Interact. 2016, 29, 313-323. [CrossRef]

17. Papasotiriou, F.G.; Varypatakis, K.G.; Christofi, N.; Tjamos, S.E.; Paplomatas, E.J. Olive mill wastes: A source of resistance for plants against Verticillium dahliae and a reservoir of biocontrol agents. Biol. Control. 2013, 67, 51-60. [CrossRef]

18. Aggeli, F.; Ziogas, I.; Gkizi, D.; Fragkogeorgi, G.A.; Tjamos, S.E. Novel biocontrol agents against Rhizoctonia solani and Sclerotinia sclerotiorum in lettuce. BioControl 2020, 65, 763-773. [CrossRef]

19. Tjamos, E.C.; Tsitsigiannis, D.I.; Tjamos, S.E.; Antoniou, P.P.; Katinakis, P. Selection and Screening of Endorhizosphere Bacteria from Solarized Soils as Biocontrol Agents Against Verticillium dahliae of Solanaceous Hosts. Eur. J. Plant Pathol. 2004, 110, 35-44. [CrossRef]

20. Cochrane, S.A.; Vederas, J.C. Lipopeptides from Bacillus and Paenibacillus spp.: A Gold Mine of Antibiotic Candidates. Med. Res. Rev. 2016, 36, 4-31. [CrossRef]

21. Kim, Y.C.; Hur, J.Y.; Park, S.K. Biocontrol of Botrytis cinerea by chitin-based cultures of Paenibacillus elgii HOA73. Eur. J. Plant Pathol. 2019, 155, 253-263. [CrossRef] 
22. Jiang, C.; Li, Z.; Shi, Y.; Guo, D.; Pang, B.; Chen, X.; Shao, D.; Liu, Y.; Shi, J. Bacillus subtilis inhibits Aspergillus carbonarius by producing iturin $\mathrm{A}$, which disturbs the transport, energy metabolism, and osmotic pressure of fungal cells as revealed by transcriptomics analysis. Int. J. Food Microbiol. 2020, 330, 108783. [CrossRef]

23. Sneh, B. Use of Rhizosphere Chitinolytic Bacteria for Biological Control of Fusarium oxysporum f. sp. dianthi in Carnation. J. Phytopathol. 1981, 100, 251-256. [CrossRef]

24. Morrissey, R.; Dugan, E.; Koths, J. Chitinase production by an Arthrobacter sp. lysing cells of Fusarium roseum. Soil Biol. Biochem. 1976, 8, 23-28. [CrossRef]

25. Raaijmakers, J.M.; Vlami, M.; De Souza, J.T. Antibiotic production by bacterial biocontrol agents. Antonie Van Leeuwenhoek 2002, 81, 537-547. [CrossRef]

26. De Simone, N.; Pace, B.; Grieco, F.; Chimienti, M.; Tyibilika, V.; Santoro, V.; Capozzi, V.; Colelli, G.; Spano, G.; Russo, P. Botrytis cinerea and Table Grapes: A Review of the Main Physical, Chemical, and Bio-Based Control Treatments in Post-Harvest. Foods 2020, 9, 1138. [CrossRef]

27. Arfaoui, M.; Vallance, J.; Bruez, E.; Rezgui, A.; Melki, I.; Chebil, S.; Sadfi-Zouaoui, N.; Rey, P. Isolation, identification and in vitro characterization of grapevine rhizobacteria to control ochratoxigenic Aspergillus spp. on grapes. Biol. Control. 2019, 129, 201-211. [CrossRef]

28. Pantelides, I.S.; Christou, O.; Tsolakidou, M.-D.; Tsaltas, D.; Ioannou, N. Isolation, identification and in vitro screening of grapevine yeasts for the control of black aspergilli on grapes. Biol. Control. 2015, 88, 46-53. [CrossRef]

29. Calvo-Garrido, C.; Roudet, J.; Aveline, N.; Davidou, L.; Dupin, S.; Fermaud, M. Microbial Antagonism Toward Botrytis Bunch Rot of Grapes in Multiple Field Tests Using One Bacillus ginsengihumi Strain and Formulated Biological Control Products. Front. Plant Sci. 2019, 10, 105. [CrossRef]

30. Zhou, Q.; Fu, M.; Xu, M.; Chen, X.; Qiu, J.; Wang, F.; Yan, R.; Wang, J.; Zhao, S.; Xin, X.; et al. Application of antagonist Bacillus amyloliquefaciens NCPSJ7 against Botrytis cinerea in postharvest Red Globe grapes. Food Sci. Nutr. 2020, 8, 1499-1508.

31. Jiang, C.; Shi, J.; Liu, Y.; Zhu, C. Inhibition of Aspergillus carbonarius and fungal contamination in table grapes using Bacillus subtilis. Food Control. 2014, 35, 41-48. [CrossRef]

32. Filonow, A.B. Role of Competition for Sugars by Yeasts in the Biocontrol of Gray Mold of Apple. Biocontrol Sci. Technol. 1998, 8, 243-256. [CrossRef]

33. Adikaram, N.K.B.; Joyce, D.C.; Terryc, L.A. Biocontrol activity and induced resistance as a possible mode of action for Aureobasidium pullulans against grey mould of strawberry fruit. Australas. Plant Pathol. 2002, 31, 223-229.

34. Walters, D.R.; Ratsep, J.; Havis, N.D. Controlling crop diseases using induced resistance: Challenges for the future. J. Exp. Bot. 2013, 64, 1263-1280. [CrossRef]

35. Saito, S.; Michailides, T.J.; Xiao, C.L. Fungicide-resistant phenotypes in Botrytis cinerea populations and their impact on control of gray mold on stored table grapes in California. Eur. J. Plant Pathol. 2019, 154, 203-213. [CrossRef]

36. Giannakis, C.; Bucheli, C.S.; Skene, K.G.M.; Robinson, S.P.; Scott, N.S. Chitinase and $\beta-1,3-$ glucanase in grapevine leaves: A possible defence against powdery mildew infection. Aust. J. Grape Wine Res. 1998, 4, 14-22. [CrossRef]

37. Derckel, J.-P.; Baillieul, F.; Manteau, S.; Audran, J.-C.; Haye, B.; Lambert, B.; Legendre, L. Differential Induction of Grapevine Defenses by Two Strains of Botrytis cinerea. Phytopathology 1999, 89, 197-203. [CrossRef]

38. Robert, N.; Roche, K.; Lebeau, Y.; Breda, C.; Boulay, M.; Esnault, R.; Buffard, D. Expression of grapevine chitinase genes in berries and leaves infected by fungal or bacterial pathogens. Plant Sci. 2002, 162, 389-400. [CrossRef]

39. Nie, P.; Li, X.; Wang, S.; Guo, J.; Zhao, H.; Niu, D. Induced Systemic Resistance against Botrytis cinerea by Bacillus cereus AR156 through a JA/ET- and NPR1-Dependent Signaling Pathway and Activates PAMP-Triggered Immunity in Arabidopsis. Front. Plant Sci. 2017, 8, 238. [CrossRef]

40. Chu, K.; Ng, T. Isolation of a large thaumatin-like antifungal protein from seeds of the Kweilin chestnut Castanopsis chinensis. Biochem. Biophys. Res. Commun. 2003, 301, 364-370. [CrossRef]

41. Ho, V.S.; Wong, J.H.; Ng, T. A thaumatin-like antifungal protein from the emperor banana. Peptides 2007, 28, 760-766. [CrossRef]

42. Vigers, A.J.; Wiedemann, S.; Roberts, W.K.; Legrand, M.; Selitrennikoff, C.P.; Fritig, B. Thaumatin-like pathogenesis-related proteins are antifungal. Plant Sci. 1992, 83, 155-161. [CrossRef]

43. Fierens, E.; Rombouts, S.; Gebruers, K.; Goesaert, H.; Brijs, K.; Beaugrand, J.; Volckaert, G.; Van Campenhout, S.; Proost, P.; Courtin, C.M.; et al. TLXI, a novel type of xylanase inhibitor from wheat (Triticum aestivum) belonging to the thaumatin family. Biochem. J. 2007, 403, 583-591. [CrossRef]

44. Shah, J.M.; Singh, R.; Veluthambi, K. Transgenic rice lines constitutively co-expressing tlp-D34 and chi11 display enhancement of sheath blight resistance. Biol. Plant. 2013, 57, 351-358. [CrossRef]

45. Tobias, D.J.; Manoharan, M.; Pritsch, C.; Dahleen, L.S. Co-bombardment, integration and expression of rice chitinase and thaumatin-like protein genes in barley (Hordeum vulgare cv. Conlon). Plant Cell Rep. 2006, 26, 631-639. [CrossRef]

46. Grover, A. Plant Chitinases: Genetic Diversity and Physiological Roles. Crit. Rev. Plant Sci. 2012, 31, 57-73. [CrossRef]

47. Kaku, H.; Nishizawa, Y.; Ishii-Minami, N.; Akimoto-Tomiyama, C.; Dohmae, N.; Takio, K.; Minami, E.; Shibuya, N. Plant cells recognize chitin fragments for defense signaling through a plasma membrane receptor. Proc. Natl. Acad. Sci. USA 2006, 103, 11086-11091. [CrossRef]

48. Mauch, F.; Mauch-Mani, B.; Boller, T. Antifungal hydrolases in pea tissue: II. Inhibition of fungal growth by combinations of chitinase and b-1,3-glucanase. Plant Physiol. 1988, 88, 936-942. 
49. Reddy, M.; Patrick, Z. Colonization of tobacco seedling roots by fluorescent pseudomonad suppressive to black root rot caused by Thielaviopsis basicola. Crop. Prot. 1992, 11, 148-154. [CrossRef]

50. Dimakopoulou, M.; Tjamos, S.E.; Antoniou, P.P.; Pietri, A.; Battilani, P.; Avramidis, N.; Markakis, E.A.; Tjamos, E.C. Phyllosphere grapevine yeast Aureobasidium pullulans reduces Aspergillus carbonarius (sour rot) incidence in wine-producing vineyards in Greece. Biol. Control. 2008, 46, 158-165.

51. Sánchez, C.; Villacreses, J.; Blanc, N.; Espinoza, L.; Martinez, C.; Pastor, G.; Manque, P.; Undurraga, S.F.; Polanco, V. High quality RNA extraction from Maqui berry for its application in next-generation sequencing. SpringerPlus 2016, 5, 1-7. [CrossRef]

52. Kortekamp, A. Expression analysis of defence-related genes in grapevine leaves after inoculation with a host and a non-host pathogen. Plant Physiol. Bioch. 2006, 44, 58-67.

53. Reid, K.E.; Olsson, N.; Schlosser, J.; Peng, F.; Lund, S.T. An optimized grapevine RNA isolation procedure and statistical determination of reference genes for real-time RT-PCR during berry development. BMC Plant Biol. 2006, 6, 27. 